\title{
SALVIA FRUTICOSA-MEDIATED ANTIOXIDANT PROTECTION AGAINST OXIDATIVE STRESS IN STREPTOZOTOCIN - INDUCED DIABETIC RATS ROLE OF A-GLUCOSIDASE ACTIVITY
}

\author{
Alaaeldin Ahmed Hamza ${ }^{1}$, Samir Mohamed Ahmed ${ }^{2}$ and Hanan Mohamed Elwy 3 Omyma K. \\ Radwan 4 \\ ${ }^{1}$ National Organization for Drug Control and Research (NODCAR), Hormone Evaluation Department \\ ${ }^{2}$ Children's Hospital of Ain Sahams University, Nutrition Department \\ ${ }^{3}$ National Organization for Drug Control and Research (NODCAR), Physical Chemistry department \\ ${ }^{4}$ National Organization for Drug Control and Research (NODCAR), Physiology department
}

\begin{abstract}
Oxidative stress is involved in the development and progression of diabetic complications. Salvia fruticosa was reported to have a protective action against oxidative stress. In the present study, diabetes was induced in male Wister rats using streptozotocin (60 mg/ $\mathrm{kg}$ body weight). Diabetic rats exhibit not only the symptoms of diabetes like the loss of body weight, hyperglycemia, polyuria and polydipsia but oxidative stress. Daily ingestion of $1 \mathrm{gm} / \mathrm{kg}$ of body weight of Salvia fruticosa extract for 60 days to diabetic rats reversed the adverse effect of diabetes on rats. Salvia fruticose extract provides better control of glucose levels and body weight loss. In heart, kidney, and liver, diabetes-induced changes in lipid peroxidation marker (malondialdehyde) were entirely attenuated by Salvia fruticose treatment. This was accompanied by a significant decrease in reduced glutathione and superoxide dismutase activity and increase in catalase activity in these tissues. Results from this study indicate that Salvia fruticosa extract modulates the adverse effect of diabetes on streptozotocin-induced diabetic rats. SF extract was evaluated for in vitro antioxidant capacity by estimating of total phenolics content, the ferric reducing antioxidant power (FRAP) assay, 1,1-diphenyl-2-picryhydrazyl (DPPH), and ABTS assays. The extract was found to inhibit a $\alpha$ glucosidase activity similar to acarbose. Salvia fruticosa extract may have a potential therapeutic effect due to its antioxidant and anti-hyperglycemic properties
\end{abstract}

\section{KEY WORDS}

Salvia fruticosa, Antioxidants capacity, $\alpha$-glucosidase activity, Oxidative stress, Diabetic rats.

\section{INTRODUCTION}

Diabetes-induced oxidative stress is the key factor responsible for the onset of its complications ${ }^{1-5}$. There is growing evidence that excess generation of reactive oxygen species (ROS), largely due to hyperglycemia, causes oxidative stress in a variety of tissues of diabetic patients ${ }^{6}$. One of the main goals of treatment of diabetes is to prevent its complications and several studies confirmed that antioxidant treatment reduces diabetic complications ${ }^{7-10}$. The antioxidant protective effect of natural plants is promising therapeutic drugs for free radical pathologies 4,10-11. Among natural plants, Salvia fruticosa Mill (SF) and other Salvia species (Lamiaceae) are found to have antioxidant effect ${ }^{12-14}$. SF (Salvia triloba) is a native plant of the Mediterranean, which has been used in traditional 
medicine by many Asian and Middle Eastern countries to treat several common healthy complications such as cold, headaches, and abdominal pain ${ }^{15-16}$. The aqueous and oil extracts of SF have been shown to possess antioxidant, anti-inflammatory, anticancer and antimicrobial activities ${ }^{16}$. Salvia species are generally known for their multiple pharmacological effects including their anti-bacterial ${ }^{17}$, anti-hyperglycaemic ${ }^{18-}$ 20, anti- cancer ${ }^{21}$ and anti cholestatic 22 effects. However, the extract of SF has not received much attention in comparison to Salvia officinalis extracts. Phytochemically, salvia species contain several phenolic compounds that prevent peroxidative damage to tissues such as salvianolic acids, rosmarinic acid, carnosol, coffeic acid tanshinone IIA, and another phenolic glycosides ${ }^{23-26}$.

Considering the importance of oxidative stress in the pathophysiology of diabetic complications, the purpose of this study was to characterize changes in antioxidative defence and oxidative stress in the heart, liver and kidney of diabetic rats and to evaluate whether these changes can be prevented or attenuated by ethanolic extract of SF. Experimental diabetes was induced by administrating a single streptozotocine (STZ) dose. SF protection was assessed via monitoring the marker of lipid peroxidation (LP) in tissues (malondialdehyde (MDA)), endogenous antioxidants (reduced glutathione (GSH), superoxide dismutase (SOD) and catalase (CAT) enzyme activities) and total antioxidant capacity (TAC). The in vitro antioxidant properties of SF were achieved through investigating the radical-scavenging effects, including DPPH, and ABTS assays and the ferric reducing antioxidant power (FRAP) assay.

\section{MATERIALS AND METHODS}

\section{Chemicals}

Thiobarbituric acid, reduced glutathione, 5,5-dithiobis (2-nitrobenzoic acid), Folin's reagent, epinephrine, SOD enzyme, H2O2, Streptozotocin and bovine albumin 2,4,6-tripyridyl triazine, gallic acid, sodium carbonate, 1,1-diphenyl-2-picrylhydrazyl (DPPH), the $\alpha$ Glucosidase enzyme from Saccharomyces cerevisiae, 4nitrophenyl $\alpha$-D-glucopyranoside were obtained from Sigma Chemical Co. (St. Louis, MO). All other chemicals purchased from common commercial suppliers.

\section{Preparation of Plant Extract:}

Fresh SF was collected during the flowering period in March and April 2015 from southern Mediterranean region at altitudes ranging from 200 to $400 \mathrm{~m}$ at the littoral of Beirut, Lebanon. The plant was dried under shade at $25^{\circ} \mathrm{C}$ and the dried aerial parts were purchased from a local herbal store (Cairo, Egypt). The plant was botanically authenticated by Dr. Nael M. Fawzi, Flora and Taxonomy Department, Agricultural Research Center, Giza, Egypt. A voucher specimen was deposited at the herbarium of the Flora and Taxonomy Department, Giza, Egypt.

To increase the yield of extraction in a shorter time and a lower temperature, the liquid-phase microwaveassisted process was used for extraction of SF according to the methods described by Pan et al. ${ }^{27}$ and Alfaro et al. ${ }^{28}$. These microwave-assisted extraction applications are based upon the selective and localized heating of particular components within the material being treated. When the material is immersed in a solvent that is transparent to microwaves (ethanol and water), the resulting increases in localized temperature and pressure cause the target compounds to migrate from the material to the relative cold solvent surrounding. The air-dried plant material was crushed in a grinder. A sample of 100 gms of ground- dried plants were extracted with $1000 \mathrm{ml}$ of $70 \%(\mathrm{v} / \mathrm{v})$ aqueous ethanol. The extract was irradiated with microwave for two minutes. The extract was then filtered through gauze, after overnight maceration, and ethanol evaporated under reduced pressure at $40^{\circ} \mathrm{C}$ by using a rotary evaporator. Then the water extract was dried by using a freeze dry system under reduced pressure. The dried extract was dissolved in distilled water before administration to normal and diabetic animals.

\section{In vitro antioxidant properties}

Total antioxidant properties of SF were estimated by the total phenolic content (TPC) the ferric reducing antioxidant power (FRAP), 1,1-diphenyl-2picrylhydrazyl $\quad\left(\mathrm{DPPH}^{\circ}\right), \quad 2, \quad$ 2-azino-bis ethylbenzothiazoline-6-sulfonate) (ABTS+). TPC was determined by the method of 29 using the FolinCiocalteu reagent and expressed in milligrams of gallic acid equivalent per $g$ dry weight of plant material. The FRAP assay was determined according to the method of Benzie 30 and DPPH and ABTS methods were determined as previously described 31. IC50 value $(\mathrm{mg} / \mathrm{mL})$ is the concentration of extract that causes 
DPPH radical is scavenged by $50 \%$. In ABTS assay, the calibration curve of ascorbic acid was established, the antioxidant capacity of the SF was then expressed as $\mu \mathrm{mol}$ ascorbic acid equivalent/g dry extract.

\section{In vitro $\alpha$-Glucosidase inhibition assay}

The $\alpha$-glucosidase enzyme inhibitory assay was performed in a 96 well plate as described earlier the papers 32. $\alpha$-Glucosidase $(25 \mu \mathrm{l}, 0.5 \mathrm{U} / \mathrm{ml})$ in $100 \mathrm{mM}$ potassium phosphate buffer $(\mathrm{pH} 6.8)$ were mixed with $25 \mu \mathrm{l}$ of test sample. Acarbose $(1 \mathrm{mg} / \mathrm{ml})$ was also assayed as a standard reference and incubated at $25{ }^{\circ} \mathrm{C}$ for $15 \mathrm{~min}$. After the incubation $25 \mu \mathrm{L}$ of the substrate4-nitrophenyl $\alpha$-D-glucopyranoside

(1 $\mathrm{mM}$ concentration in $100 \mathrm{mM}$ potassium phosphate buffer, $\mathrm{pH}$ 6.8) were added to the mixture. The enzymatic reaction was allowed to proceed at $25^{\circ} \mathrm{C}$ for $10 \mathrm{~min}$ and was stopped by the addition of $100 \mu \mathrm{L}$ of $0.2 \mathrm{M}$ sodium carbonate. Nitrophenol absorption was measured at $405 \mathrm{~nm}$ using an Elisa Reader. The percent inhibition of $\alpha$-glucosidase was calculated as $\{1$-(Abs Sample-Abs blank)/Abs control\} $\times 100$, where Abs sample represents the absorbance of the experimental sample, Abs blank represents the absorbance of the blank, and Abs control represents the absorbance of the control. The IC50 value was defined as the concentration of $\alpha$-glucosidase inhibitor that inhibited $50 \%$ of $\alpha$-glucosidase activity. Nonlinear regression (with sigmoidal dose response) was used to calculate thelC50 values of using Origin Pro v8.

\section{Animals}

The Healthy adult male Wistar rats ( 8 weeks old, 130$180 \mathrm{~g}$ ) were obtained from the animal house of the National Research Center (Giza, Egypt). They were maintained on standard pellet diet and tap water ad libitum and were kept in polycarbonate cages with wood chip bedding under a $12 \mathrm{hr}$ light/dark cycle and room temperature $22-24^{\circ} \mathrm{C}$. Rats were acclimatized to the environment for two weeks prior to experimental use. All experiments were carried out in accordance with research protocols established by the animal care committee of the National Research Center, Egypt, which followed the recommendations of the National Institutes of Health Guide for Care and Use of Laboratory Animals (Publication No. 85-23, revised 1985).

\section{Acute toxicity test}

The acute toxicity of the crude ethanolic extract of SF was determined by using male rats (150-200g), according to the method described by Ahmad et al., 33 . Rats were randomly grouped into four groups and in per group; rats were doused with 250, 5001000 and $2000 \mathrm{mg} / \mathrm{kg}$ of the SF extract orally via gastric gavage. All animals were observed for any kind of behavioral changes, physical and pharmacological toxic effects at 0,30 and $60 \mathrm{~min}, 24,48$ and $72 \mathrm{~h}$ and 1 week after administration. They were no observed over a period of one week for signs of toxicity and mortality.

\section{Induction of experimental diabetes}

Diabetes induced by injection a single intraperitoneal dose of STZ $60 \mathrm{mg} / \mathrm{kg}$ body weight and was freshly prepared in $0.01 \mathrm{M}$ citrate buffer, $\mathrm{pH} 4.5$ as described previously 34 . The control rats were injected with the same volume of citrate buffer. STZ injected animals were given $20 \%$ glucose solution overnight to overcome drug induced hypoglycemic mortality. Diabetes was identified by polydipsia, polyuria and measuring blood glucose concentration 72 hours after injection of STZ. Blood samples were taken from the tail vein. The blood glucose level was determined by glucose oxidase method using a one touch basic plus glucometer (Lifescane LId., California, USA). Rats with a blood glucose level above $250 \mathrm{mg} \mathrm{/} \mathrm{dl} \mathrm{were}$ considered diabetic and were used in this study.

\section{Treatment schedule}

The rats were divided into three groups with 10 rats in each group and were treated through a gavage tube for a period of for 8 weeks as follows: The diabetic rats were randomly divided into two sub - groups with or without SF. SF was given orally by gavage at a dose level of one gm per $\mathrm{kg}$ of body weight, daily for 8 weeks. The control animals received equivalent volume of distilled water based on body weight.

\section{Sample Preparation}

After 8 weeks of SF or vehicle solution administration, animals were fasted overnight and blood glucose levels were determined using glucometer, and then the rats anaesthetized with diethyl ether anesthesia. The animals were sacrificed by cervical dislocation and one gm of heart, kidney and liver were removed and homogenized in ice-cold potassium chloride (150 mM). The ratio of tissue weight to homogenization buffer was 1:10. From the latter, suitable dilutions for determination of the levels of GSH, LP product MDA, total proteins, and activities of SOD and CAT were prepared in suitable different buffers.

\section{Biochemical Assays}


The GSH content in the tissue homogenate was determined using the method described by Van Dooran et al 35 . The basis of the GSH determination method is the reaction of Ellman's reagent 5,5-dithiobis (2-nitrobenzoic acid) (DTNB) with thiol group of GSH at $\mathrm{pH} 8.0$ to give yellow color of 5-thiol-2- nitrobenzoate anion.

Malondialdehyde is the most abundant individual aldehyde resulting from LP breakdown in biological systems and used as an indirect index of LP, the determination of MDA in biological materials, as described in Aksoy et $\mathrm{al}^{8}$, is based on its reaction with thiobarbituric acid (TBA) to form a pink complex with absorption maximum at $535 \mathrm{~nm}$.

The total antioxidant capacity in tissues was evaluated using ferric reducing antioxidant power (FRAP) assay. The FRAP assay was determined according to the method described by Benzie and Strain. ${ }^{30}$. The FRAP assay measures the change in absorbance at $593 \mathrm{~nm}$ due to the formation of a blue colored ferroustripyridyltriazine complex from colourless oxidized ferric form by the action of electron donating antioxidants.

The activity of SOD enzyme in tissue homogenates was determined according to the method described by Sun \& Zigman ${ }^{36}$. This method is based on the ability of SOD to inhibit the auto-oxidation of epinephrine at alkaline $\mathrm{pH}$ to adrenochrome and other derivatives, which are easily monitored in the near-UV region of the absorption spectrum. CAT activity was determined by measuring the exponential disappearance of $\mathrm{H} 2 \mathrm{O} 2$ at $240 \mathrm{~nm}$ and expressed as units/mg of protein as described by Aebi ${ }^{37}$.

The total protein content in tissues was determined according to the Lowry,s method modified by ${ }^{38}$. In all the estimations, Absorbance was recorded using a PerkinElmer, Lambda 25 UV/VIS spectrophotometer in all measurements.

Standardization of the aqueous extract using RP-HPLC Rosmarinic acid and carnosol were selected as a marker for HPLC standardization as it was the major bioactive compound we previously isolated from the SF. The dry residue of SF ethanol extract ( $20 \mathrm{mg}$ ) was dissolved in $10 \mathrm{~mL}$ of methanol and $20 \mu \mathrm{l}$ aliquot were analysis by HPLC. The separation was carried out on
HPLC apparatus (Waters 600E system controller coupled with a photodiode array detector, Water 990 series). $20 \mu$ l of aliquot were injected into a reverse phase NOVA-PAK C18, $20 \times 3.9 \mathrm{~mm}$ i.d., particle size $420 \mu \mathrm{m})$ at $20^{\circ} \mathrm{C}$. The mobile phase was acetonitril (A) and acidified water containing $2.5 \%$ formic acid (B). The gradient was as follows: 0 min, $5 \%$ A; $10 \mathrm{~min}, 15 \% \mathrm{~A} ; 30$ $\min , 25 \%$ A, $35 \mathrm{~min}, 30 \%$ A; 50 min, 55\% A; 55 min 90\% $A ; 60 \mathrm{~min}, 100 \% \mathrm{~A}$ and then hold for $10 \mathrm{~min}$ before returning to the initial conditions. The flow rate was 1.0 $\mathrm{ml} / \mathrm{min}$ and wavelengths were $280 \mathrm{~nm}$. Serial dilutions of standard of rosmarinic acid and carnosol were prepared from a stock solution having a final concentration $^{39}$. A standard calibration curve was established using the different concentrations. Each sample was injected in triplicates.

\section{Statistical Analysis}

The data are expressed as group mean \pm SEM. SPSS (version 20) statistical program (SPSS Inc., Chicago, IL, USA) was used to carry out a one-way analysis of variance (ANOVA) on our data. When significant differences by ANOVA were detected, analysis of differences between the means of the treated and control groups were performed by using Dunnett's t test.

\section{RESULTS}

\section{Acute toxicity studies}

Animals showed good tolerance to testing (250, 500, 1000 and $2000 \mathrm{mg} / \mathrm{kg}$ ) doses of SF extract. Extract in doses as high as $2 \mathrm{~g} / \mathrm{kg}$ that were found to be nonlethal. Highest dose of extract did not show any noticeable signs of toxicity and mortality after once daily administration orally for 7 days. Therefore, the extract is safe for long-term administration.

Effect of SF on body weight change and blood glucose concentration in STZ-induced diabetic rats

Diabetic rats exhibited decreased in final body weight and increased in blood glucose concentration when compared to the normal control group. Treatment with ethanol extract of SE effectively attenuated the decrease in body weight and the increase in blood glucose level in diabetic rats (Table1).

Table 1. Effect of SF on body weight changes and blood glucose in STZ-induced diabetic rats.

\begin{tabular}{|c|c|c|c|}
\hline Groups & Control & Diabetic & Diabetic +SF \\
\hline
\end{tabular}




\begin{tabular}{lccc}
\hline Body weight changes $(\mathrm{g})$ & $60.00 \pm 1.58$ & $-19.00 \pm 8.35^{* * *}$ & $11.80 \pm 5.52^{* * *}$ \\
Blood glucose $(\mathrm{mg} / \mathrm{dl})$ & $74.60 \pm 0.60$ & $435.60 \pm 7.44^{* * *}$ & $193.00 \pm 37.24^{* *}$
\end{tabular}

Dennett's $\mathrm{t}$ test was performed after ANOVA test. Data are means $\pm \mathrm{SEM},{ }^{* *} \mathrm{P}<0.01,{ }^{* * *} \mathrm{P}<0.001$ vs. control.

Effect of SF on MDA and TAC in STZ-induced diabetic rats

STZ treated rats showed a significant increase in marker of LP. We measured LP as MDA. Diabetic control rats showed significantly elevated levels of MDA in heart $(P<0.001)$, liver $(P<0.01)$ and kidney $(P$
$<0.001$ ) tissues. SF completely prevented the elevation in MDA level (Figure $1 \mathrm{~A}$ ). The TAC decreased in heart $(P<0.001)$, liver $(P<0.001)$ and kidney $(P<0.05)$ of diabetic rats. Whereas, the SF treatment prevented the depletion in TAC in diabetic animals (Figure $1 \mathrm{~B}$ ).

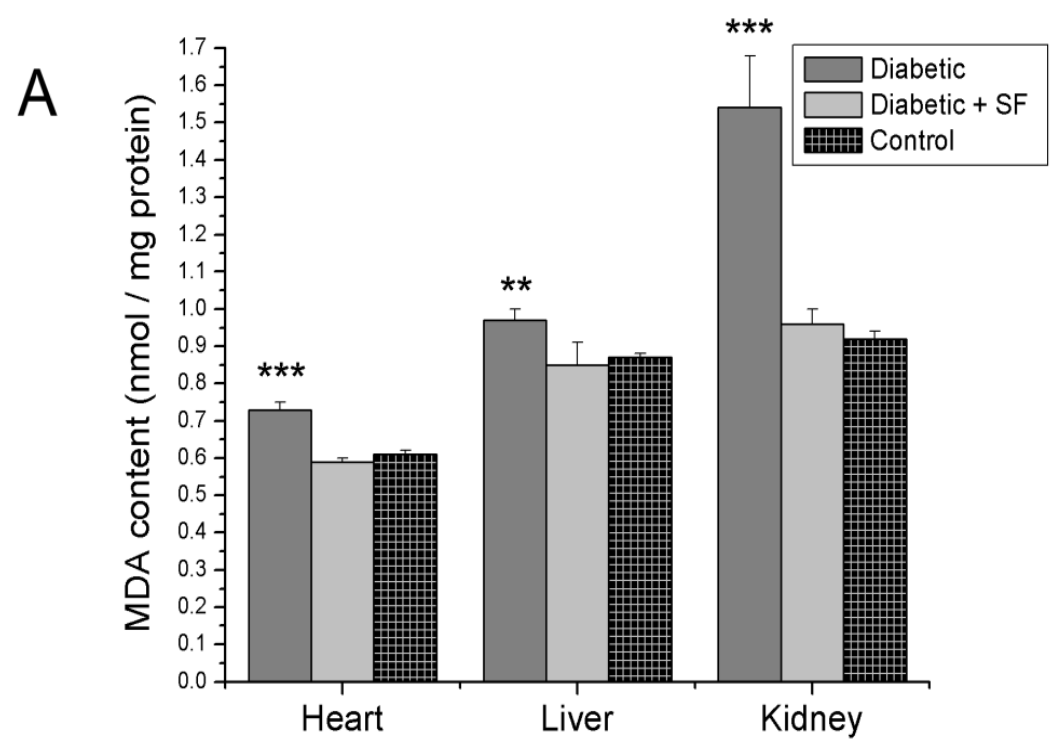

B

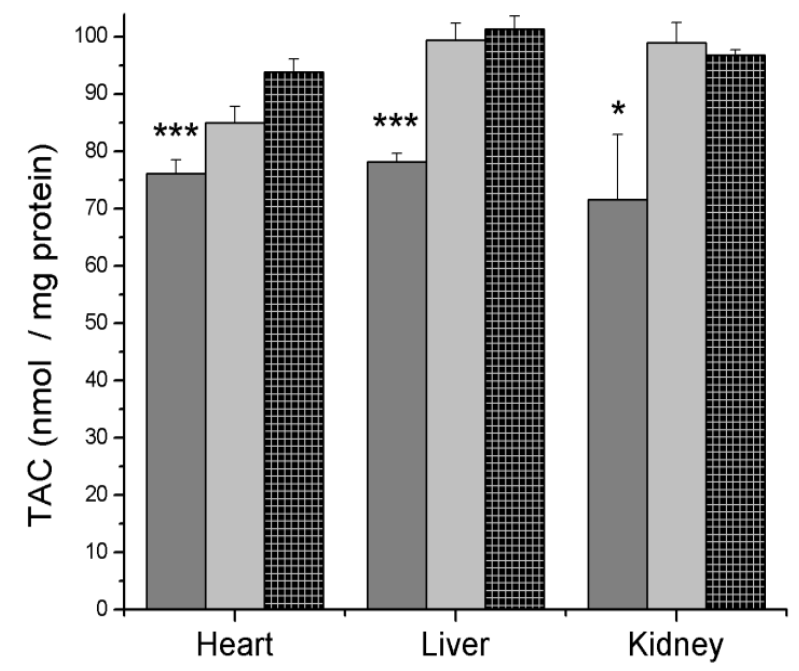

Figure 1. Effect of treatment with SF on (A) MDA) and (B) TAC in heart, liver and kidney of diabetic rats. Dennett's t test was performed after ANOVA test.

Each column represents the mean $\pm \operatorname{SEM}(n=6) .(n=6) .{ }^{*} \mathrm{P}<0.05, * * P<0.01, * * * P<0.001$ vs. control. 
Effect of SF on CAT, SOD and GSH in STZ-induced diabetic rats

Although CAT activity was increased in heart $(P<0.05)$ and kidney $(P<0.05)$ of diabetic rats, there was a significant decrease $(P<0.01)$ in liver. The repeated treatment with SF completely prevented these changes in CAT (Figure $2 \mathrm{~A}$ ). In STZ-treated rats, SOD activity was significant increase in heart $(P<0.01)$, liver $(P<0.001)$ and kidney $(P<0.01)$. While the repeated treatment with SF completely prevented this effect in diabetic rats (Figure 2 B). STZ induced elevation in cardiac $(P<0.05)$ and renal $(P<0.001)$ GSH levels while hepatic GSH content significantly decreased $(P<0.05)$. These changes in GSH contents were completely prevented by SF (Figure $2 \mathrm{C}$ ).

\section{A}

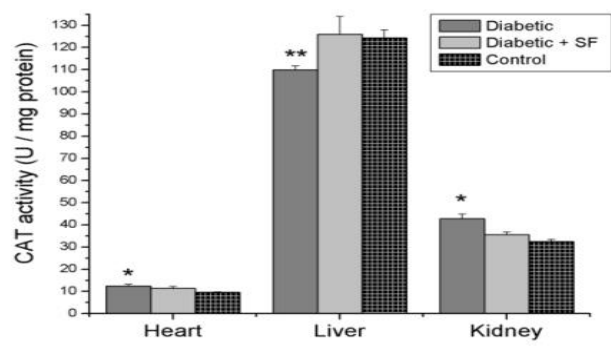

B
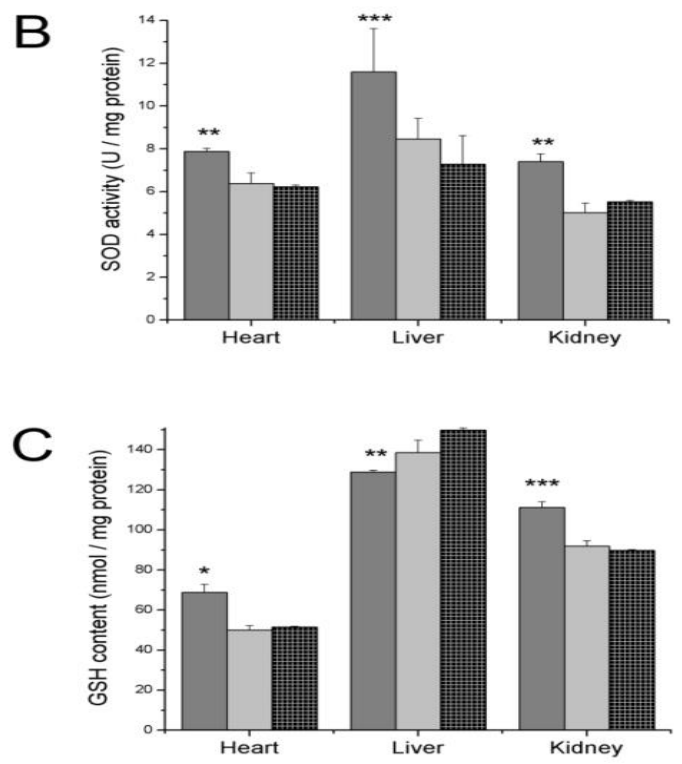

Figure 2. Effect of treatment with SF on (A) CAT, (B) SOD and (C) GSH in heart, liver and kidney of diabetic rats. Dennett's $t$ test was performed after ANOVA test. Each column represents the mean $\pm \operatorname{SEM}(n=6) .{ }^{*} P<0.05, * *$ $\mathrm{P}<0.01, * * * \mathrm{P}<0.001$ vs. control.

\section{In vitro antioxidant Activity of SF}

In the present work, the TFC, FRAP, ABTS and DPPH• were used to test the antioxidant activities of SF extracts. The results of the three assays are summarized in Table 2. The TFC of SF was measured using Folin-Ciocalteau's assay expressed in mg of gallic acid the plant extract has $25.5 \pm 0.73 \mathrm{mg}$ gallic acid/ $\mathrm{g}$. FRAP assay depends on reduction of oxidized ferric ions to ferrous ions by antioxidant. The reducing capacity of compound may serve as a significant indicator of its potential antioxidant activity. In the present study, each gram of dried SF has high FRAP value, $17.16 \mu \mathrm{mol}$ ascorbic acid equivalent/g. Additionally, the ABTS and DPPH radical- scavenging methods are widely used for evaluating the ability of plant extracts to scavenge free radical generated from ABTS and DPPH reagents. The SF exhibited high anti free radical scavenging activity where the ascorbic acid equivalent antioxidant capacities of the SF were 30.16 $\pm 0.12 \mu \mathrm{mol} / \mathrm{g}$ in $\mathrm{ABTS}$ and The $\mathrm{DPPH}$ radical scavenging ability of samples (IC50) was $44.95 \pm 2.52$ $\mu \mathrm{g} / \mathrm{mL}$. 
Table 2. In vitro antioxidant capacity of SF.

\begin{tabular}{lllll}
\hline Assay & $\begin{array}{l}\text { TPC } \\
\text { Assay }\end{array}$ & FRAP Assay & ABTS Assay & DPPH Assay \\
& & TAC & TAC $(\mu \mathrm{mol} / \mathrm{g})$ & $\mathrm{IC}_{50}(\mu \mathrm{g} / \mathrm{mL})$ \\
& $\mathrm{mg} / \mathrm{g}$ & $(\mu \mathrm{mol} / \mathrm{g})$ & & \\
\hline SF & $25.50 \pm 0.73$ & $17.16 \pm 0.42$ & $30.16 \pm 0.12$ & $44.95 \pm 2.52$
\end{tabular}

Total antioxidant activity of SF is expressed as ascorbic acid equivalents ( $\mu \mathrm{mol} / \mathrm{g}$ of dry extract). Total phenolic content (TPC) is expressed as gallic acid equivalents ( $\mathrm{mg} / \mathrm{g}$ of dry extract). Values are means $\pm \mathrm{SME}$ of three experiments.

\section{$\alpha$-Glucosidase inhibitory activity of SF}

The $\alpha$-glucosidase inhibitory activity of SF was depicted in Figure 3. The result showed that the extracts inhibited $\alpha$-glucosidase activity dosedependently (12.5-50 lg/mL) As was shown in Figure 3, the $\alpha$-glucosidase inhibitory activities increased with the gradually increased concentration of SF. Based on IC50 values, $\alpha$-glucosidase inhibitory activity of SF (IC50 $=167.4 \mu \mathrm{g} / \mathrm{mL}$ ) was lower than that of acarbose standard reference $(202.65 \mu \mathrm{g} / \mathrm{mL})$.

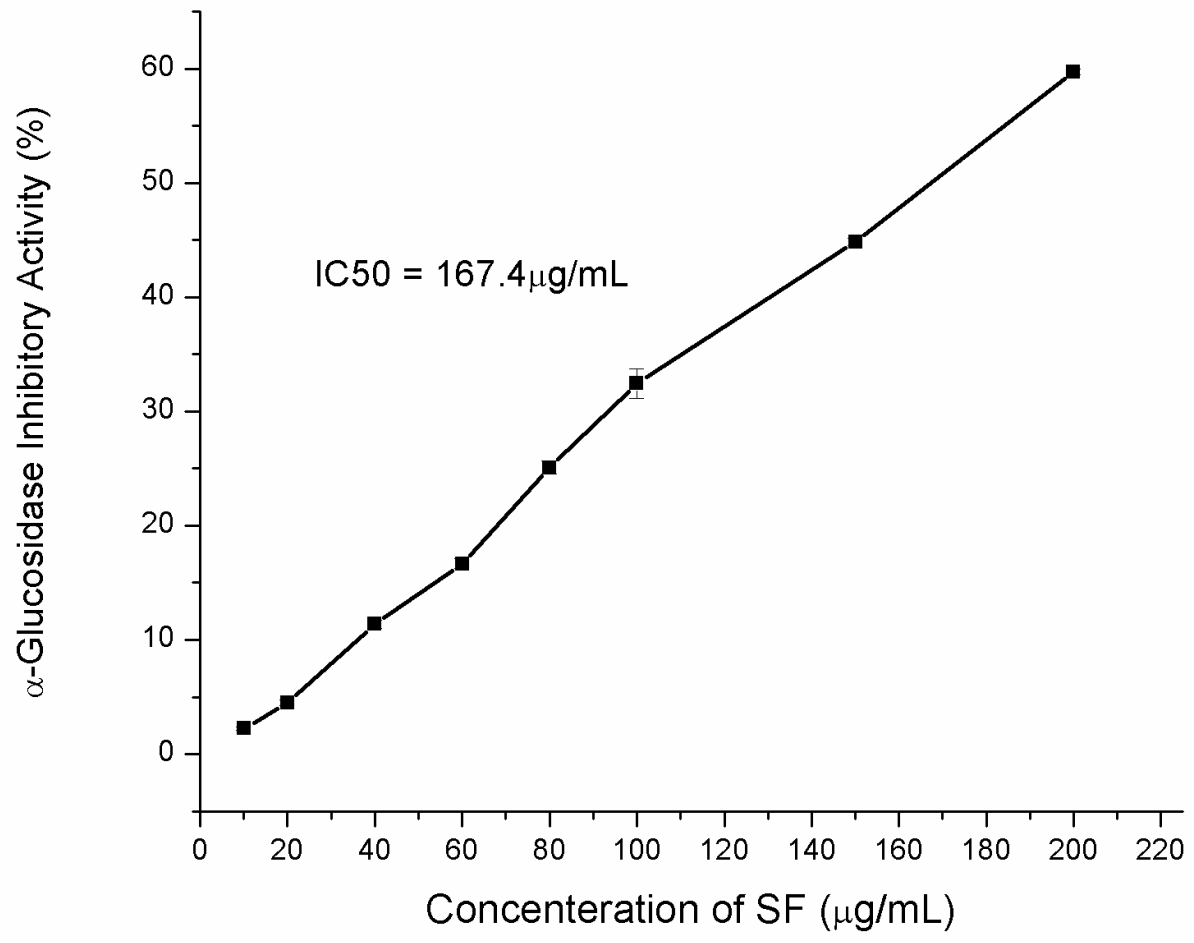

Figure 3. Dose-dependent changes in $\alpha$-glucosidase inhibitory activity of $S F\left(I C_{50}=167.4 \mu \mathrm{g} / \mathrm{mL}\right.$ of dried sample). Values are means \pm SME of three experiments.

\section{Standardizations of SF by HPLC}

The HPLC profile of SF extract was run in parallel to the corresponding standards under similar analytical conditions. The HPLC analysis of rosmarinic acid and carnosol of rosemary crud extract are shown in Figure 4 and Table 3. HPLC analysis of SF extract revealed the presence of some chromatographic peaks among which are rosmarinic acid at $17.654 \mathrm{~min}$ and carnosol at $50.246 \mathrm{~min}$. HPLC quantitative analysis showed that rosmarinic acid content was $3.0 \mathrm{mg}$ per g SF crud extract while carnosol was $4.5 \mathrm{mg}$ per $\mathrm{g}$ of SF crud extract. 

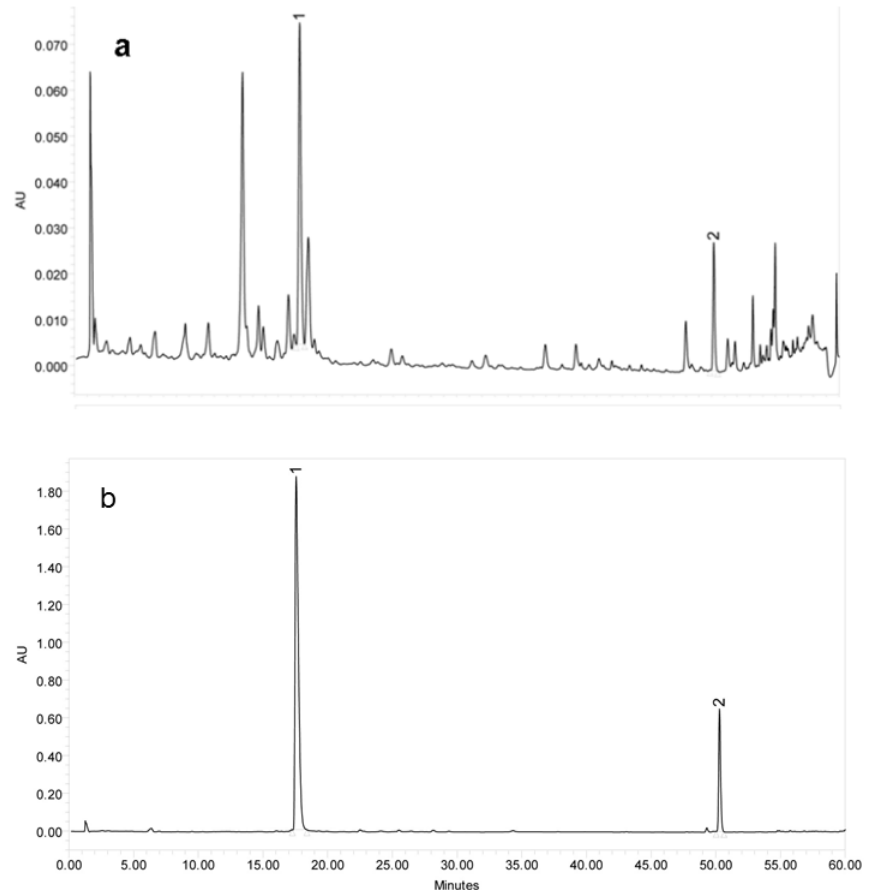

Figure 4. Representative HPLC profile of SE ethanol extract at $280 \mathrm{~nm}$ (a), run in parallel to the rosmarinic acid and carnosol standards (b) under similar analytical conditions. Rosmarinic acid (peak 1), carnosol (peak2), Values are means \pm S.E.M. of three experiments.

Table 3. The quantitative analyses of the SF ethanol extract carried out using an HPLC.

\begin{tabular}{lllll}
\hline SE extract & Peak No & Active ingredient & RT & Concentration \\
\hline 1 & Rosmarinic acid & 17.65 & $3.0 \mathrm{mg} / \mathrm{g}$ \\
& 2 & Carnosol & 50.25 & $4.5 \mathrm{mg} / \mathrm{g}$ \\
\hline
\end{tabular}

Values are means \pm SME of three triplicate experiments.

\section{DISCUSSION}

The present study exhibited the protection effect of SF against STZ-induced oxidative stress in heart, kidney and liver of rats. The anti-oxidative stress of SF was confirmed by its antioxidants properties in vitro study. In the present study, we clearly showed that SF markedly decreased hyperglycemia in STZinduced diabetic rats and restored the loss of body weight. In the present study, STZ administration caused an increase in the LP and decreases TAC in diabetic rats when compared to normal rats. MDA is the end product of LP 40 and TAC considers the cumulative action of all the antioxidants present in the body ${ }^{41}$. The increase in lipid peroxidation might be an indication of a decrease in enzymatic and nonenzymatic antioxidants of defense mechanisms. Oxidative stress is the common player for the major pathways associated with development and progression of diabetic complications $1,4,10,42,43$. Oxidative stress damage was confirmed in the present STZ-treated rats by the increased in MDA level and the decreased in TAC in diabetic heart, kidney and liver, which is consistent with other studies ${ }^{8,44-46}$. The increase in oxygen-free radicals in diabetic condition could be due to increase in blood glucose levels, which generate free radicals upon auto oxidation. In fact, increased generation of ROS such as superoxide, hydrogen peroxide and hydroxyl radicals have been shown to occur in diabetes in association with hyperglycemia ${ }^{47}$. Glucose autooxidation, protein glycation and protein kinase activation are the main mechanisms of increased production of ROS in hyperglycemia and diabetes ${ }^{2,4}$ 48 . One of the main challenges of research in recent years is to attenuate oxidative stress in order to improve diabetes ${ }^{6,10}$. In our study, the treatment 
with SF completely prevented the elevation in MDA and the depletion in TAC induced in diabetic rats. This indicates that SF played a protective role in the diabetic tissues during oxidative damage.

Cells possess a plenty of cytoprotective enzymes, which protect living cells from oxidative stressinduced damage. The antioxidant enzymes CAT and SOD are the first line of defense against free radicalinduced tissue damage ${ }^{40}$. The current work showed a significant increase in CAT and SOD enzyme activities in the heart, kidney and liver of diabetic rats except CAT activity showed a decrease in the diabetic liver. Diabetes was previously shown to increase CAT and SOD activities in heart ${ }^{8,46,49,50}$ and in kidney ${ }^{8,9}$ of rats. These up regulations in CAT and SOD enzymes could be explained by the compensatory mechanisms in tissues to overcome the oxidative stress and may be response to increase production of hydrogen peroxide and superoxide radicals. In this line, Weidig et al 47 observed that increased generation of ROS in coronary microvascular endothelial cells under the effect of hyperglycemia increased the expression and activity of CAT, SOD and glutathione peroxidase enzymes. On the other hand, the decrease in hepatic CAT activity of diabetic rats, which previously observed ${ }^{51}$ may be due to oxidative stress induced inactivation and / or consumption of enzyme. The treatment with SF prevented these alterations in antioxidant enzymes in diabetic rats.

GSH serve as sensitive marker of oxidative stress and it plays an important role in maintaining the integrity of mitochondria and cell membranes 52,53. GSH content was significantly decreased in liver of diabetic rats, which was concomitant with previous studies 54, 55. In contrast, GSH contents were significantly increased in heart and kidney of the same diabetic animals. This compensatory increase in GSH content in heart and kidney was previously reported in other studies ${ }^{8,56}$. Because GSH is mainly synthesized in the liver ${ }^{57}$, the decrease in hepatic GSH observed here could be resulted from increase its consumption by other tissues. In the present work, SF administration normalized GSH contents in heart, liver and kidney of diabetic rats.

The antioxidant activity exhibited by SF could be one of the reasons for the protective effect of plant against oxidative stress in diabetic rats. The antioxidant potential of SF was also measured by scavenging activity on ABTS and DPPH radicals and reducing ability by FRAP assay. Present investigation showed that the SF exhibited significantly higher ABTS and DPPH scavenging activities, which demonstrates a potent hydrogen-donating ability of this plant. It has been established that salvia species and some of its constituents, mainly phenolic compounds such as salvianolic acids, rosmarinic acid, carnosol, coffeic acid and other phenolic glycosides $12,25,24,26$ have antioxidant effects in vivo and in vitro studies. However, the treatment with SF not only prevented the oxidative stress but also attenuated the hyperglycemic effects of diabetes. Several species of salvia including SF found to have antihyperglycemic effect in alloxan-induced diabetic animals $18,20,57$. Hyperglycemia is not only generated more ROS but also attenuates antioxidative mechanisms through glycation of the antioxidant enzymes ${ }^{2,47}$. So the possibility of anti-hyperglycemic effect of SF could not rule out for the protective effect offered in SF-treated diabetic rats. The possible mechanism by which SE brings about its anti-hyperglycemic action may be by inhibition of the breakdown of disaccharides to liberate glucose. Intestinal $\alpha$-glucosidase catalyzes the breakdown of disaccharides to liberate glucose, which is later absorbed into the blood circulation. Inhibition of this enzyme would slow down the breakdown of starch in the gastro-intestinal tract, thus reducing postprandial hyperglycemia. SF extract exhibited remarkable inhibitory activities against $\alpha$ Glucosidase $\left(\mathrm{IC}_{50}=167.4 \mu \mathrm{g} / \mathrm{mL}\right)$.

\section{CONCLUSION}

Oxidative stress induced by diabetes could play a crucial role in the development and progression of diabetic complication and of SF could be a potential therapeutic agent for diabetic oxidative damage due to its antioxidant and anti- hyperglycemic properties.

\section{ACKNOWLEDGMENT}

There are no conflicts of interest regarding each of the authors involved in this research study.

\section{REFERENCES}


1. Kakkar R, Mantha SV, Radhi J, Prasad K, Kalra J. Increased oxidative stress in rat liver and pancreas during progression of streptozotocin-induced diabetes. Clinical Science. 1998; 94:623-32.

2. Ha H, Kim KH. Pathogenesis of diabetic nephropathy: the role of oxidative stress and protein kinase $C$. Diabetes research and clinical practice. 1999; 45:14751.

3. Kikkawa R, Koya D, Haneda M. Progression of diabetic nephropathy. American journal of kidney diseases. 2003;41: S19-S21.

4. Ceriello A, Testa R, Genovese S. Clinical implications of oxidative stress and potential role of natural antioxidants in diabetic vascular complications. Nutrition, Metabolism and Cardiovascular Diseases. 2016; 26:285-92.

5. Domingueti CP, Dusse LMSA, das Graças Carvalho $M$, de Sousa LP, Gomes KB, Fernandes AP. Diabetes mellitus: The linkage between oxidative stress, inflammation, hypercoagulability and vascular complications. Journal of diabetes and its complications. 2015; 30:738-45.

6. Rochette L, Zeller M, Cottin Y, Vergely C. Diabetes, oxidative stress and therapeutic strategies. Biochimica et Biophysica Acta (BBA)-General Subjects. 2014; 1840:2709-29.

7. Cay M, Nazırog `lu M, Simsek H, Aydilek N, Aksakal M, Demirci $M$. Effects of intraperitoneally administered vitamin $C$ on antioxidative defense mechanism in rats with diabetes induced by streptozotocin. Research in Experimental Medicine. 2001; 200:205-13.

8. Aksoy N, Vural H, Sabuncu T, Aksoy S. Effects of melatonin on oxidative-antioxidative status of tissues in streptozotocin-induced diabetic rats. Cell biochemistry and function. 2003; 21:121-5.

9. Yildirim $O$, Büyükbingöl Z. In vivo effect of vitamin C with cobalt on oxidative stress in experimental diabetic rat kidney. Diabetes, nutrition \& metabolism. 2003; 16:208-13.

10. Rani V, Deep G, Singh RK, Palle K, Yadav UC. Oxidative stress and metabolic disorders: Pathogenesis and therapeutic strategies. Life sciences. 2016; 148:18393.

11. Repetto M, Llesuy S. Antioxidant properties of natural compounds used in popular medicine for gastric ulcers. Brazilian journal of medical and biological research. 2002; 35:523-34.

12. Wang $M$, Shao Y, Li J, Zhu N, Rangarajan M, LaVoie EJ, et al. Antioxidative phenolic glycosides from sage (Salvia officinalis). Journal of Natural Products. 1999; 62:454-6.

13. Zupkó I, Hohmann J, Redei D, Falkay G, Janicsak G, Máthé I. Antioxidant activity of leaves of Salvia species in enzyme-dependent and enzyme-independent systems of lipid peroxidation and their phenolic constituents. Planta Medica. 2001; 67:366-8.

14. Boukhary R, Raafat K, Ghoneim Al, Aboul-Ela M, ElLakany A. Anti-Inflammatory and Antioxidant Activities of Salvia fruticosa: An HPLC Determination of Phenolic Contents. Evidence-Based Complementary and Alternative Medicine. 2016;2016.

15. Gali-Muhtasib H, Hilan C, Khater C. Traditional uses of Salvia libanotica (East Mediterranean sage) and the effects of its essential oils. Journal of ethnopharmacology. 2000; 71:513-20.

16. Gali-Muhtasib H. Anticancer and medicinal properties of essential oil and extracts of East Mediterranean sage (Salvia triloba). Advances in Phytomedicine. 2006; 2:169-80.

17. Miski M, Ulubelen A, Johansson C, Mabry TJ. Antibacterial activity studies of flavonoids from Salvia palaestina. Journal of Natural Products. 1983; 46:8745.

18. Perfumi M, Arnold N, Tacconi R. Hypoglycemic activity of Salvia fruticosa Mill. from Cyprus. Journal of ethnopharmacology. 1991; 34:135-40.

19. Alarcon-Aguilara F, Roman-Ramos R, Perez-Gutierrez $S$, Aguilar-Contreras A, Contreras-Weber C, FloresSaenz J. Study of the anti-hyperglycemic effect of plants used as antidiabetics. Journal of ethnopharmacology. 1998; 61:101-10.

20. Hosseinzadeh $H$, Haddad Khodaparast $M$, Shokoohizadeh H. Antihyperglycemic activity of Salvia leriifolia Benth. leaf and seed extracts in mice. Iran J Basic Med Sci. 1998; 4:94-8.

21. Liu J, Shen H-M, Ong C-N. Salvia miltiorrhiza inhibits cell growth and induces apoptosis in human hepatoma HepG 2 cells. Cancer letters. 2000; 153:8593.

22. Oh S-H, Nan J-X, Sohn D-H, Kim Y-C, Lee B-H. Salvia miltiorrhiza inhibits biliary obstruction-induced hepatocyte apoptosis by cytoplasmic sequestration of p53. Toxicology and applied pharmacology. 2002; 182:27-33.

23. Cao E-H, Liu X-Q, Wang J-J, Xu N-F. Effect of natural antioxidant tanshinone II-A on DNA damage by lipid peroxidation in liver cells. Free Radical Biology and Medicine. 1996; 20:801-6.

24. Hohmann J, Zupkó I, Rédei D, Csányi M, Falkay G, Máthé $I$, et al. Protective effects of the aerial parts of Salvia officinalis, Melissa officinalis and Lavandula angustifolia and their constituents against enzymedependent and enzyme-independent lipid peroxidation. PLANTA MEDICA: NATURAL PRODUCTS AND MEDICINAL PLANT RESEARCH. 1999; 65:576-8. 
25. Lu Y, Foo LY, Wong H. Sagecoumarin, a novel caffeic acid trimer from Salvia officinalis. Phytochemistry. 1999; 52:1149-52.

26. Santos-Gomes PC, Seabra RM, Andrade PB, Fernandes-Ferreira M. Phenolic antioxidant compounds produced by in vitro shoots of sage (Salvia officinalis L.). Plant Science. 2002; 162:981-7.

27. Pan X, Niu G, Liu H. Microwave-assisted extraction of tanshinones from Salvia miltiorrhiza bunge with analysis by high-performance liquid chromatography. Journal of Chromatography A. 2001; 922:371-5.

28. Alfaro MJ, Bélanger JM, Padilla FC, Paré JJ. Influence of solvent, matrix dielectric properties, and applied power on the liquid-phase microwave-assisted processes $\left(\mathrm{MAP}^{\mathrm{TM}}\right.$ ) extraction of ginger (Zingiber officinale). Food Research International. 2003; 36:499-504.

29. Singleton VL, Orthofer R, Lamuela-Raventos RM. Analysis of total phenols and other oxidation substrates and antioxidants by means of folinciocalteu reagent. In: Packer L, editor. Methods in Enzymology. San Diego,London, New York, Tokyo.: Academic Press, Harcourt Brace \& Company.; 1999. p. 152-78.

30. Kumar D, Gupta N, Ghosh R, Gaonkar RH, Pala BC. Glucosidase and $\alpha$-amylase inhibitory constituent of Carex baccans: Bio-assay guided isolation and quantification by validated RP-HPLC-DAD. Journal of Functional Foods. 2013; 5:211-8.

31. Ahmad W, Khan I, Khan MA, Ahmad M, Subhan F, Karim N. Evaluation of antidiabetic and antihyperlipidemic activity of Artemisia indica linn (aeriel parts) in Streptozotocin induced diabetic rats. Journal of ethnopharmacology. 2014; 151:618-23.

32. Yanardag R, Bolkent S, Karabulut-Bulan Ö, Tunali S. Effects of vanadyl sulfate on kidney in experimental diabetes. Biological trace element research. 2003; 95:73-85.

33. Van Doorn R, Leijdekkers C-M, Henderson PT. Synergistic effects of phorone on the hepatotoxicity of bromobenzene and paracetamol in mice. Toxicology. 1978; 11:225-33.

34. Benzie IF, Strain J. The ferric reducing ability of plasma (FRAP) as a measure of "antioxidant power": the FRAP assay. Analytical biochemistry. 1996; 239:70-6.

35. Sun $M$, Zigman $S$. An improved spectrophotometric assay for superoxide dismutase based on epinephrine autoxidation. Analytical biochemistry. 1978; 90:81-9.

36. Aebi H. Catalase. Meth Enzymol. 1984; 105:121-26.

37. Peterson GL. A simplification of the protein assay method of Lowry et al. which is more generally applicable. Analytical biochemistry. 1977; 83:346-56.
38. Wang SP, Huang KJ. Determination of flavonoids by high-performance liquid chromatography and capillary electrophoresis. . J Chromatogr. 2004; 1032:273-9.

39. Betteridge DJ. What is oxidative stress. Metabolism 2000; 49:3-8.

40. Ghiselli A, Serafini M, Natella F, Scaccini C. Total antioxidant capacity as a tool to assess redox status: critical view and experimental data. Free Radical Biology and Medicine. 2000; 29:1106-14.

41. Maritim A, Sanders R, Watkins Jr. Effects of $\alpha$-lipoic acid on biomarkers of oxidative stress in streptozotocin-induced diabetic rats. The Journal of nutritional biochemistry. 2003; 14:288-94.

42. Obrosova IG, Fathallah L, Liu E, Nourooz-Zadeh J. Early oxidative stress in the diabetic kidney: effect of DL- $\alpha$ lipoic acid. Free Radical Biology and Medicine. 2003; 34:186-95.

43. Abdollahi M, Salehnia A, Mortazavi SHR, Ebrahimi M, Shafiee A, Fouladian F, et al. Antioxidant, antidiabetic, antihyperlipidemic, reproduction stimulatory properties and safety of essential oil of Satureja Khuzestanica in rat in vivo: a toxicopharmacological study. Medical Science Monitor. 2003;9:BR331-BR5.

44. Gupta S, Kataria M, Gupta P, Murganandan S, Yashroy R. Protective role of extracts of neem seeds in diabetes caused by streptozotocin in rats. Journal of ethnopharmacology. 2004; 90:185-9.

45. Cumaoğlu A, Ozansoy G, Irat AM, Arıcıoğlu A, Karasu C, Arı N. Effect of long term, non-cholesterol lowering dose of fluvastatin treatment on oxidative stress in brain and peripheral tissues of streptozotocindiabetic rats. European Journal of Pharmacology 2011; 654:80-5.

46. Weidig P, McMaster D, Bayraktutan U. High glucose mediates pro-oxidant and antioxidant enzyme activities in coronary endothelial cells. Diabetes, Obesity and Metabolism. 2004; 6:432-41.

47. Giugliano D, Ceriello A, Paolisso G. Oxidative stress and diabetic vascular complications. Diabetes care. 1996; 19:257-67.

48. Ozansoy G, Akin B, Aktan F, Karasu C. Short-term gemfibrozil treatment reverses lipid profile and peroxidation but does not alter blood glucose and tissue antioxidant enzymes in chronically diabetic rats. Molecular and Cellular Biochemistry. 2001; 216:59-63.

49. Okutan H, Ozcelik N, Yilmaz HR, Uz E. Effects of caffeic acid phenethyl ester on lipid peroxidation and antioxidant enzymes in diabetic rat heart. Clinical Biochemistry. 2005; 38:191-6.

50. Singh N, Kamath V, Rajini P. Attenuation of hyperglycemia and associated biochemical 
parameters in STZ-induced diabetic rats by dietary supplementation of potato peel powder. Clinica chimica acta. 2005; 353:165-75.

51. Ookhtens $M$, Kaplowitz $N$. Role of the liver in interorgan homeostasis of glutathione and cyst (e) ine. Seminars in liver disease1997. p. 313-29.

52. Deneke SM. Thiol-based antioxidants. Curr Top Cell Regul. 2000; 36:445.

53. Otsyula M, King MS, Ketcham TG, Sanders RA, Watkins JB. Oxidative stress in rats after 60 days of hypergalactosemia or hyperglycemia. International journal of toxicology. 2003; 22:423-7.

54. Sevenl A, Gfizell S, Seymenz O, Civelekl S, Bolay1r113 $M$, Uncul M. Effects of Vitamin E Supplementation on Oxidative Stress in Streptozotocin Induced Diabetic
Rats: Investigation of. Yonsei medical journal. 2004; 45:703-10.

55. Yue KK, Chung W-s, Leung AW, Cheng $\mathrm{CH}$. Redox changes precede the occurrence of oxidative stress in eyes and aorta, but not in kidneys of diabetic rats. Life sciences. 2003; 73:2557-70.

56. Deneke SM, Fanburg BL. Regulation of cellular glutathione. American Journal of Physiology-Lung Cellular and Molecular Physiology. 1989;257: L163L73.

57. Shabana M, Mirhom Y, Genenah A, Aboutabl E, Amer H. Study into wild Egyptian plants of potential medicinal activity. Ninth communication: hypoglycaemic activity of some selected plants in normal fasting and alloxanised rats. Archiv fur experimentelle Veterinarmedizin. 1989; 44:389-94. 